\title{
Factors that affect Transition of Children from Pre School to Primary Level School
}

\author{
Shah Fahad \\ Teacher Iqra International school \& college
}

\begin{abstract}
The progress of kids from preschool to formal or primary school is viewed as one of the most basic times of the students. Consequently, as of late, incredible accentuation has been given on kids' effective passage in essential instruction. The reason for this paper is to record the assessments of Pakistani instructors on which youngsters are bound to experience challenges in their progress to the following teaching level. The overview was completed on an example of 500 Primary and preschool teachers from the whole district of Mardan \& Swabi Kp Pakistan instructive region. The Tools that was utilized was a closed ended questionnaire type. It was too investigated how their reactions shifted by their activity position (preschool instructors, elementary teachers and school heads). The teachers accept that the most significant factors that are identified with the fruitful change of children to primary school incorporate the cultural, socio-economic conditions and the relational connections of kids in preschool, their great relations with instructors, their capacity to adhere to the standards sets by school, yet additionally guardians'/parents trust towards instructors.
\end{abstract}

Keywords Pre \& Primary school, Cultures, socio-economic, Standards sets by school, Parents Trusts. 